\title{
Сравнительная карпология рода Cardiocrinum (Endl.) Lindl. (Liliaceae) Comparative carpology of the genus Cardiocrinum (Endl.) Lindl. (Liliaceae)
}

\author{
Иовлев П. С. ${ }^{1}$, Бобров А. В. ${ }^{1}$, Здравчев Н. С. ${ }^{2}$, Кандидов М. В. ${ }^{1}$ \\ Iovlev P. S. ${ }^{1}$, Bobrov A. V. F. Ch. ${ }^{1}$, Zdravchev N. S. ${ }^{2}$, Kandidov M. V. ${ }^{1}$ \\ ${ }^{1}$ Московский государственный университет имени М. В. Ломоносова, г. Москва, Россия. \\ E-mails: iovlev.petr@gmail.com,avfch_bobrov@mail.ru,mvkandidov@mail.ru \\ ${ }^{1}$ M. V. Lomonosov Moscow State University, Moscow, Russia \\ ${ }^{2}$ Главный ботанический сад имени Н. В. Цицина РАН, г. Москва, Россия. E-mail: zdravchevnikita@yandex.ru \\ ${ }^{2}$ N. V. Tsitsin Main Botanical Garden RAS, Moscow, Russia
}

Peфepam. Произведено анатомическое исследование перикарпия зрелого плода Cardiocrinum cordatum (Thunb.) Makino. Было установлено, что у рода Cardiocrinum верхняя локулицидно вскрывающаяся коробочка, структура перикарпия которой позволяет отнести ее к переходному типу между Lilium-типом с одревесневающим эндокарпием и Galanthus-типом, в перикарпии которого отсутствует одревесневающая зона. Особенности строения перикарпия дает дополнительные основания к выделению Cardiocrinum в самостоятельный род семейства лилейных.

Ключевые слова. Коробочка Galanthus-типа, коробочка Lilium-типа, перикарпий, экзокарпий, эндокарпий.

Summary. The anatomy of pericarp of the mature fruit of Cardiocrinum cordatum (Thunb.) Makino was investigated. It was revealed, that the fruit of Cardiocrinum is a superior loculicidal capsule. The anatomy of its pericarp allow to treat the fruit as a transitional type of capsules between Lilium-type (the endocarp is lignified) and Galanthus-type (no lignification occurs in any zone of the pericarp). The peculiarities of pricarp structure of Cardiocrinum supports its treatmend as a separate genus of the Liliaceae family.

Key words. Capsule of the Lilium-type, capsule of the Galanthus-type, endocarp, exocarp, pericarp.

Cardiocrinum Endl. изначально был описан как одна из 5 секций рода Lilium L. (Endlicher, 1836), но затем был выделен в отдельный род (Lindley, 1846). Разными авторами виды Cardiocrinum рассматривались в ранге самостоятельного рода (Buxbaum, 1937; Liang, 1995; Matthews, 2002), тогда как другие включали их в род Lilium s. 1. (Wilson, 1925; Comber, 1949). Филогенетические исследования также показывают близкое родство Cardiocrinum и Lilium, вместе с морфологически близкими Notholirion и Fritillaria. Cardiocrinum составляет отдельную кладу семейства Liliaceae (Hayashi, Kawano, 2000). В настоящее время в роде выделяют 3 вида: тибетско-гималайский Cardiocrinum giganteum (Wall.) Makino, Cardiocrinum cathayanum (E. H. Wilson) Stearn из Центрального Китая и Cardiocrinum cordatum (Thunb.) Makino, распространенный на Японских островах, Южных Курилах и Сахалине (Liang, 1995; Ohara et al., 2006; Yang et al., 2017).

Для изучения морфологии и анатомического строения перикарпия плоды Cardiocrinum cordatum на средних и поздних стадиях развития были собраны в Главном ботаническом саду им. Н. В. Цицина РАН и в Ботаническом саду ГБПОУ «Воробьевы горы», зафиксированы в 70\%-м растворе этанола. С использованием стандартных методик (Прозина, 1960; O’Brien, McCully, 1981) были изготовлены временные препараты поперечных срезов плодов в средней части. Препараты были изучены с помощью светового микроскопа Olympus CX41. Микрофотографирование произведено при помощи подключенной к микроскопу через адаптер цифровой камеры Canon EOS 7D Mark II.

Плод Cardiocrinum cordatum - верхняя локулицидная синкарпная многосеменная коробочка, развивающаяся из тримерного синкарпного гинецея, типичного для семейства Liliaceae (Dahlgren et al., 
1985; Krause, 1930; Tamura, 1998). Семена многочисленные в каждом гнезде, плоские, округло-треугольные в очертании, светло-коричневые или коричневые, окаймлены узким пленчатым крылом.

На рис. 1 представлена морфология созревающих и полностью зрелых (вскрывшихся) плодов Cardiocrinum cordatum. Для уточнения гистогенеза тканей зрелого перикарпия было выборочно изучено анатомическое строение плода на нескольких стадиях его развития. Структура перикарпия вскрывшегося плода Cardiocrinum cordatum представлена на рис. 2. Экзокарпий представлен 1-2 слоями вытянутых в тангенциальном направлении клеток с неравномерно утолщенными стенками. Мезокарпий состоит из 6-8 слоев тонкостенных паренхимных клеток с гранулированным содержимым. Эндокарпий однослойный, состоит из клеток с равномерно утолщенными стенками, которые, в отличие от таковых у Lilium, лигнифицированных полностью (Bobrov, Romanov, 2019), окрашиваются слабо и лишь частично (первичные клеточные оболочки остаются целлюлозными, а вторичные одревесневают очень слабо и фрагментарно). Единственными зонами перикарпия зрелого плода Cardiocrinum cordatum с типичным и полным одревеснением являются проводящие пучки (вентральные, дорзальные и латеральные).
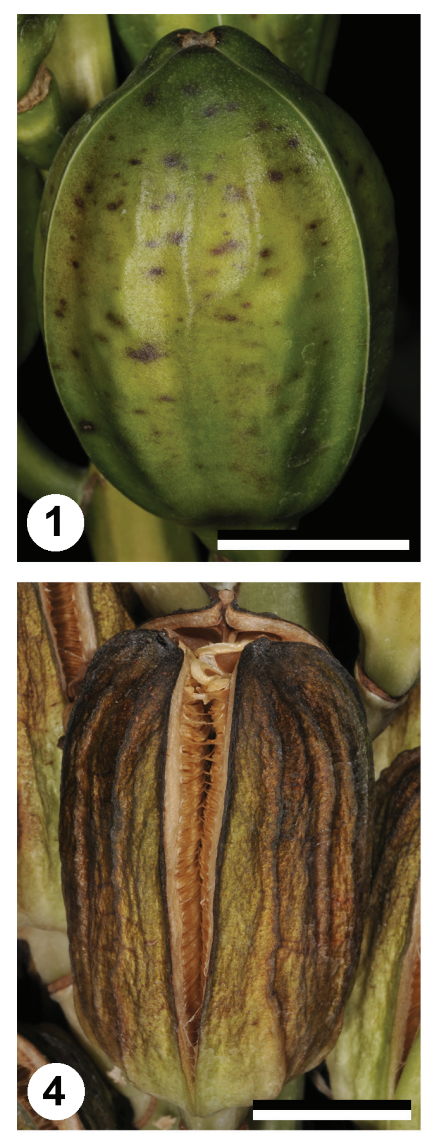
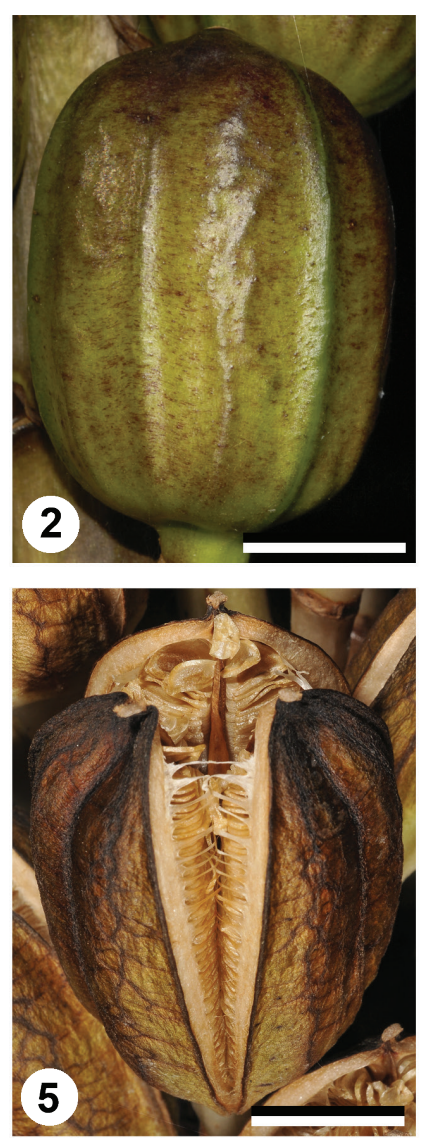
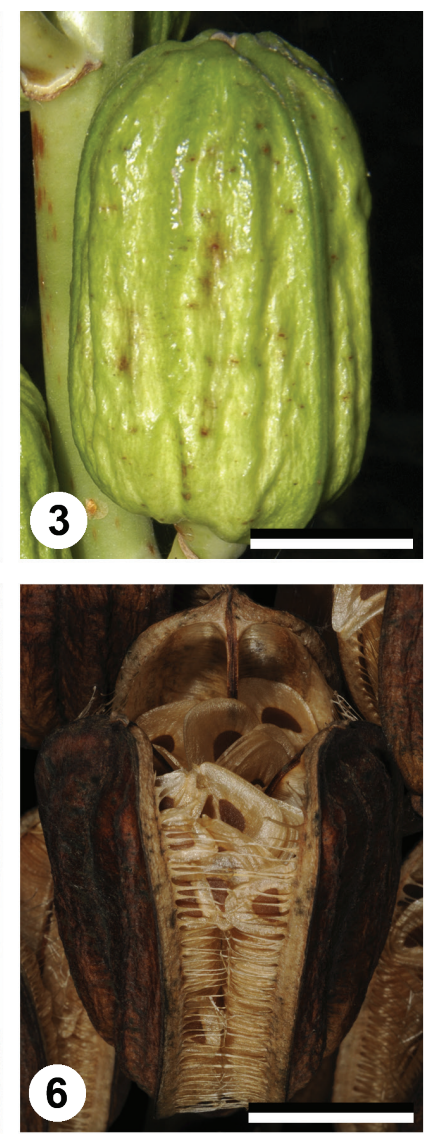

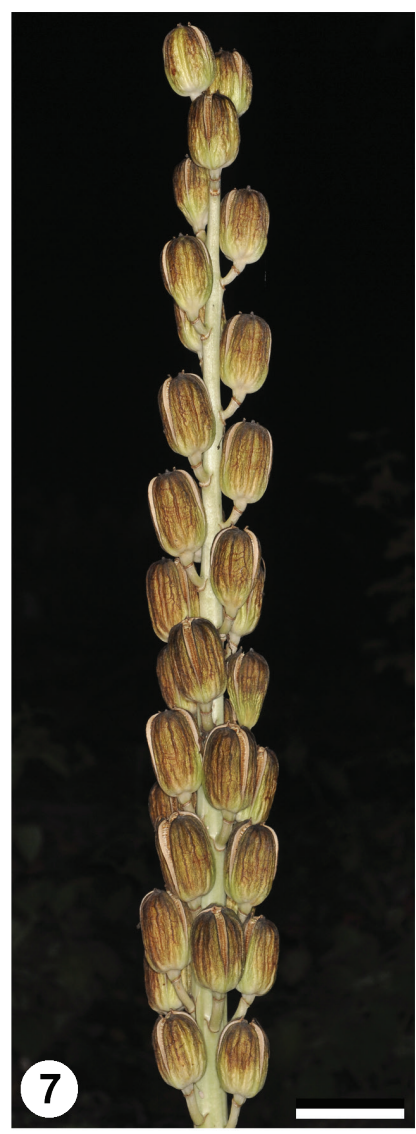

Рис. 1. 1-7 - морфология развития плода Cardiocrinum cordatum; 1-3 - I стадия; 4-5 - II стадия; 6 -III стадия; 7 внешний вид соцветия, обратите внимание на акропетальное развитие соцветия. Длина мерной линейки: $1-6-2$ см; 7. $-8 \mathrm{~cm}$.

Коробочки исследованных представителей лилиодных однодольных (порядков Liliales и Asparagales sensu APG IV, 2016) были отнесены А. В. Бобровым и М. С. Романовым (2019) к двум морфогенетическим типам: Lilium-тип (с полостью одревесневающим эндокарпием) и Galanthus-тип (в перикарпии которого выраженная зона лигнифицированных клеток отсутствует, а эндокарпий остается практически неспециализированным, мало отличаясь от внутренней эпидермы карпеллы) (Бобров и др., 2009; Bobrov, Romanov, 2019). Плод Cardiocrinum представляет собой переходный тип от коробочки 
Lilium-типа к коробочке Galanthus-типа, демонстрируя интересную с морфогенетической точки зрения стадию частичной утраты лигнификации эндокарпия. Специфическая структура перикарпия Cardiocrinuт свидетельствует, по нашему мнению, в пользу таксономической самостоятельности рода и не согласуется с включением видов Cardiocrinum в род Lilium s. 1.
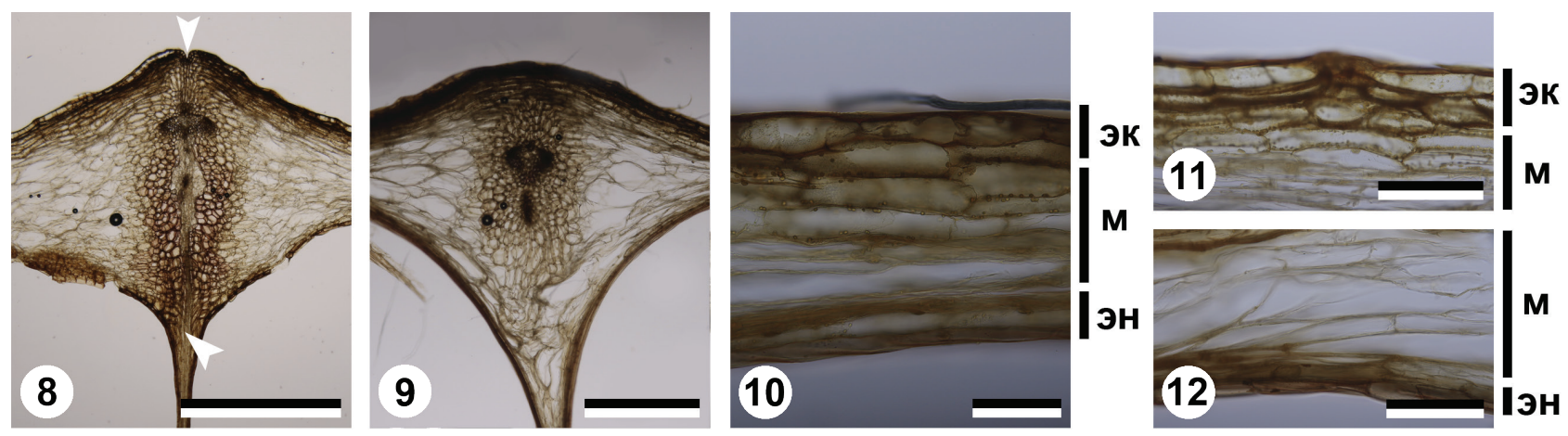

Рис. 2. 8-12 - анатомия плодов C. cordatum., поперечный срез перикарпия на III стадии развития.

8 - фрагмент перикарпия с дорзальным пучком, обратите внимание на формирование механизмов вскрывания (белые стрелки); 9 - фрагмент перикарпия с латеральным пучком; 10 - фрагмент стенки плода; 11 - Фрагмент внешней части перикарпия; 12 - Фрагмент внутренней части перикарпия. Условные обозначения: эк - экзокарпий, м - мезокарпий, эн - эндокарпий. Длина мерной линейки: 8. - 2 мм; 9. - 1 мм; 10. - 0,15 мм; 11,12. - 0,25 мм.

Работа выполнена в рамках государственного задания ГБС РАН «Биологическое разнообразие природной и культурной флоры: фундаментальные и прикладные вопросы изучения и сохранения» (№18-118021490111-5) на базе УНУ «Фондовая оранжерея».

\section{ЛИТЕРАТУРА}

Бобров А. В., Меликян А. П., Романов М. С. Морфогенез плодов Magnoliophyta. - M.: URSS, 2009 - 406 c.

Прозина М. Н. Ботаническая микротехника. - М.: Высшая школа, 1960. -205 с.

APG IV. An update of the Angiosperm Phylogeny Group classification for the orders and families of flowering plants: APG IV // Botanical Journal of the Linnean Society, 2016. - Vol. 181. - Pp. 1-20.

Bobrov A. V. F. Ch., Romanov M. S. Morphogenesis of fruits and types of fruit of angiosperms // Botany Letters, 2019. - Vol. 166. - Pp. 366-399.

Buxbaum F. Die Entwicklungslinien der Lilioideae II // Botanishe Archiv, 1937. - B. 38 - S. 213-398.

Comber H. F. A new classification of the genus Lilium // Lily Year Book, 1949. - № 13. - Pp. 86-105.

Dahlgren R. M. T., Clifford H. T. and Yeo P. F. The Families of Monocotyledons. Structure, Evolution, and Taxonomy. - Berlin: Springer, 1985. -520 pp.

Endlicher I. N. Lilium (Cardiocrinum) In: Genera plantarum secundum ordines naturales disposita. - Vienna: Fredericum Beck, 1836. -141 pp.

Hayashi K., Kawano S. Molecular systematics of Lilium and allied genera (Liliaceae): phylogenetic relationships among Lilium and related genera based on the rbcL and matK gene sequence data // Plant Species Biology, 2000. - Vol. 15. - Pp. $73-93$.

Krause K. Liliaceae. In: Engler A., Prantl K. (Eds.) Die natürlichen Pflanzenfamilien. 2nd Ed. Band 15A II. - Leipzig: W. Engelmann, 1930. - S. 227-386.

Liang SY Chorology of Liliaceae (s. str.) and its bearing on the Chinese flora // Acta Phytotaxonomica Sinica, 1995. - Vol. 33, № 1. - Pp. 27-51.

Lindley $\boldsymbol{J}$. The vegetable kingdom. - London, 1846. - 205 pp.

Matthews V. A. The Genus Cardiocrinum in Cultivation // The Plantsman, 2002. - Vol. 1, № 4. - Pp. 196-205.

O'Brien T. P., McCully M. E. The study of plant structure: principles and selected methods. - Melbourne: Termacarphy Pty. Ltd., 1981. - 357 pp.

Ohara M., Narumi T., Yoshizane T., Okayasu T., Masuda J., Kawano S. Life-history monographs of Japanese plants. 7: Cardiocrinum cordatum (Thunb.) Makino (Liliaceae) // Plant Species Biology, 2006. - Vol. 21. - Pp. 201-207. 
Tamura M. N. Liliaceae. In: Kubitzki K. (Ed.) Families and Genera of Vascular Plants. Vol. 3. - Berlin, Heidelberg: Springer, 1998 - Pp. 343-353.

Wilson E. H. The Lilies of Eastern Asia. - London, 1925. - 104 pp.

Yang L., Hu H., Xie C., Lai S., Yang M., He X, Zhou S. Molecular phylogeny, biogeography and ecological niche modelling of Cardiocrinum (Liliaceae): insights into the evolutionary history of endemic genera distributed across the Sino-Japanese floristic region // Annals of Botany, 2017. - Vol. 119. - Pp. 59-72. 